Open Access

\title{
How to tackle the slowdown of potential growth rate in China?
}

Fang Cai

Correspondence: caifang@cass.org.cn Chinese Academy of Social Sciences, 5 Jianguomennei Dajie, 100732 Beijing, China

\section{Springer}

\begin{abstract}
Background: The shrinkage of working age population at ages between 15 and 59 after 2010 will end the era of the high-speed economic growth in China. This paper is intended to explore the ways of tackling this slowdown.

Methods: By revealing annual growth rate of potential output to drop to $7.2 \%$ in 2011-2015 and $6.1 \%$ in 2016-2020, this paper is to explain the cause of growth rate deceleration and draw policy implications of such slowdown.

Results: First, the government should not seek a growth rate above potential rate if they do not intend to see distortions in the economy such as macroeconomic instability, overcapacity, deviation from comparative advantage, and protection of inefficient firms. Second, the potential growth rate can be strengthened through institutions building and reorientation of public policy in various areas in order to spur labor mobility and productivity improvement.

Conclusions: This paper suggests to deepen economic reform in order to sustain the necessarily high growth rate of the Chinese economy.

Keywords: Potential growth rate; Diminishing return to capital; Total factor productivity (TFP)
\end{abstract}

\section{Background}

During the period of dual economy, China's economic growth has been characterized by an unlimited supply of labor, which has helped to contain the rates of diminishing returns on capital. The demographic dividends lead to increased rates of savings, which in turn translated into growth in investment, ensuring ample supply of production factors. Massive flow of labor from agriculture to other industries has improved resource reallocation efficiency, and it now constitutes the main determinant of total factor productivity (TFP). Improvements in microeconomic incentive mechanism have increased technological efficiency. The wide technology gap between China and developed nations has actually benefited China via a learning process and the introduction of foreign direct investment (FDI). Through systemic reform and opening up to the outside world, China has maintained a high potential growth rate to which the actual one has been very close over the past 30 plus years.

As the working-age population (15-64) is growing at a diminishing rate and is predicted to peak in 2013, there will be a substantial reduction of agricultural surplus labor. This will in turn change the nature of the development of China's dual economy.

(c) 2015 Cai. This is an Open Access article distributed under the terms of the Creative Commons Attribution License (http:// creativecommons.org/licenses/by/2.0), which permits unrestricted use, distribution, and reproduction in any medium, provided the original work is properly credited. 
The economy will be constrained increasingly by neoclassical growth conditions. In other words, labor shortages will become common, which will cause diminishing returns on capital and shrink the window of opportunity for resource reallocation between agriculture and other industries. Not only will future economic growth be restrained by factor inputs but the potential improvement of TFP will also be reduced, causing the potential growth rate to slow down accordingly.

In response to possible slowdown of the potential growth rate, authorities will have a number of options. They may spare no effort to achieve a real growth rate higher than the potential growth rate or they may change the potential growth rate via policies. Either option will generate different results of economic results.

As is depicted in Fig. 1, two policy measures can be employed to tackle the slowdown of potential growth rate, each with different consequences. According to the current long-term aggregate supply curve $S_{1}$, more total output requires extremely high total costs. As is displayed in the figure, when the output level expands from $O_{0}$ to $O_{1}$, the total cost will rise from $C_{0}$ to $C_{2}$. With respect to the scope of the concept of total cost, one can see that it should be rather expansive, including not only the cost of the additional material input need to generate larger output but also the costs in terms of macroeconomic conditions such as inflation, resource consumption, and environmental pollution, and of other adverse market conditions associated with growth policies such as price distortion, poor resource allocative efficiency, and excess capacity. It is clear, therefore, that it can be rather dangerous to pursue a real growth rate higher than the potential growth rate.

A common mistake in macroeconomic analysis that may potentially lead to misguided policies is to confuse demand factors of economic growth with supply factors. As far as the potential growth rate is concerned, demand factors can only influence the difference, i.e., growth gap, between the real growth rate and the potential growth rate. A strong short-term demand can push the real growth rate beyond potential growth capacity, while inadequate demand can cause real growth to fall short of potential growth capacity. However, the potential of economic growth ultimately depends on the potential growth rate,

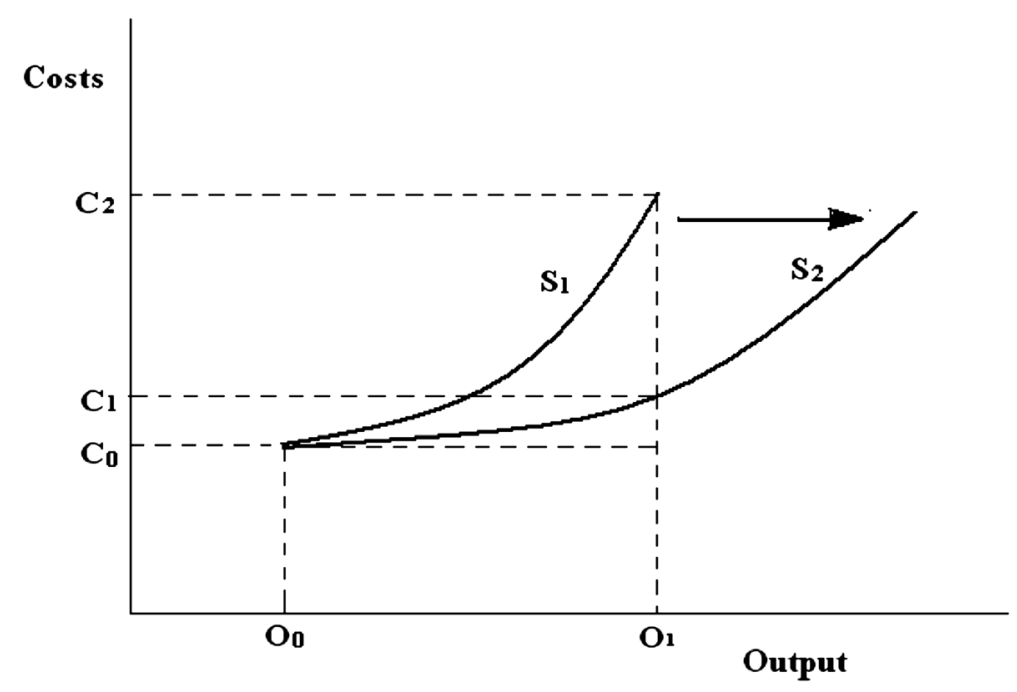

Fig. 1 Prices paid for growth under different long-term aggregate supply curves 
which is constrained by production factors on one hand and TFP on the other. Therefore, without an increase to the potential growth rate, expanding demand arbitrarily in order to spur economic growth may cause real economic growth to exceed the potential growth rate, which may also lead to distortion.

The potential growth rate of an economy is, however, changeable. For example, if price incentives are increased and the institutional environment is improved, the supply of relevant production factors may rise. In addition, the improvement of incentive mechanisms can also promote productivity gains. As shown in Fig. 1, if the long-term aggregate supply curve expands from $S_{1}$ to $S_{2}$, the same growth of total output (from $O_{0}$ to $O_{1}$ ) can be achieved at a much lower total cost (only with a rise from $C_{0}$ to $C_{1}$ ). In other words, changing the potential growth rate can result in higher economic growth rate without causing any distortion or damage to the macro economy.

This paper makes reference to some estimates for China's potential growth rate in order to explain the inevitability of its slowdown. We hope to show that the pursuit of a real rate of growth higher than the potential one by means of various distorted policies inevitably causes macroeconomic instability, thereby aggravating existing imbalances in the economic growth, and hindering the transformation of the mode of economic development in China. International experience teaches us that, however, these kinds of growth-promoting policies are in fact self-defeating.

This paper will attempt to demonstrate the plasticity of the potential growth rate. Better institutions and public policy will allow us to improve factor input, resource use efficiency, TFP, and so forth, which may increase potential growth rate, and create the conditions for higher real growth rate.

\section{Methods}

\section{Slowing of the potential growth rate}

The determining factors for the potential growth rate basically consist of labor supply, capital supply, and TFP. Production input and the sources of productivity are different for different stages of economic development. Since the launch of reform and openingup policy in 1978, and until 2004, China was a typical dual economy. In 2004, China entered a period of transition from a dual economy toward one characterized by neoclassical growth. The key determinant of the potential growth rate is the change in labor supply. When the labor supply is unlimited, diminishing return on capital, which is typical of neoclassical growth, is insignificant, meaning that cumulative growth of production factors suffice to sustain growth. Moreover, the flow of labor force from the agricultural sector to other industries can create resource reallocation efficiency, thus laying a foundation for TFP improvement, which is necessary for rapid economic growth. As a result, once the labor supply is no longer unlimited, the abovementioned conditions will undergo a fundamental change such that the slowdown of the potential growth rate is inevitable.

Demographic structure and economic growth rate can affect the absorption rate of surplus labor, and changes to the supply-demand relation in the market happen only gradually. The Lewis turning point has already been reached in China, as the growth rate of labor demand has exceeded that of labor supply, resulting in labor shortages 
and wage increases. After the Lewis turning point was reached in China in 2004, another turning point was reached, namely the demographic dividend turning point marked by the peaking of working-age population and the bottoming-out of the population dependency ratio.

According to research conducted by Japanese scholars, Japan reached the Lewis turning point in the early 1960s (Minami 1968), and if we take the start of the dependency ratio increase as signaling the turning point at which the demographic dividend dissipates, this was reached in Japan in 1990. The interval between these two turning points was about 30 years. Studies by South Korean researcher indicate that South Korea reached the Lewis turning point in 1972 (Bai 1982) and will not reach its demographic dividend turning point until 2013 or about 40 years later. In the case of China, the two points will be only 9 years apart if 2004 is regarded as the year of the Lewis turning point and 2013 as the year (when the dependency ratio will start to increase) of the demographic dividend turning point (see Fig. 2).

In terms of the demographic dividend turning point-that is, the bottoming-out and the imminent rise of the population dependency ratio and its impact on the potential growth rate-the situation in China now shares many similarities with the Japanese situation in 1970 and 1990. In 1970, Japan's dependency ratio fell to its lowest point, where it stayed until 1990. Since then, it has increased precipitously. Correspondingly, the potential growth rate of the Japanese economy slowed down significantly (Ikeda 2012 , p. 6). Hereafter, whether its real growth rate is higher or lower than its potential growth rate, forming either a positive or negative output gap, Japan's real growth rate can do no more than hovering around its potential growth rate (Amornthum 2002). In fact, Japan's average annual real GDP growth rate fell significantly, down to $3.8 \%$ between 1970 and 1990 from 9.2 \% between 1950 and 1970, after which the Japanese economy entered a period of stagnation with an average annual real GDP growth rate of $0.85 \%$ between 1990 and 2010 .

Using the growth account method, scholars have both estimated China's potential GDP growth rate between 1978 and 2009 and predicted the rate between 2010 and $2020,{ }^{1}$ and the results are quite close. For example, according to the estimates by Kuijs

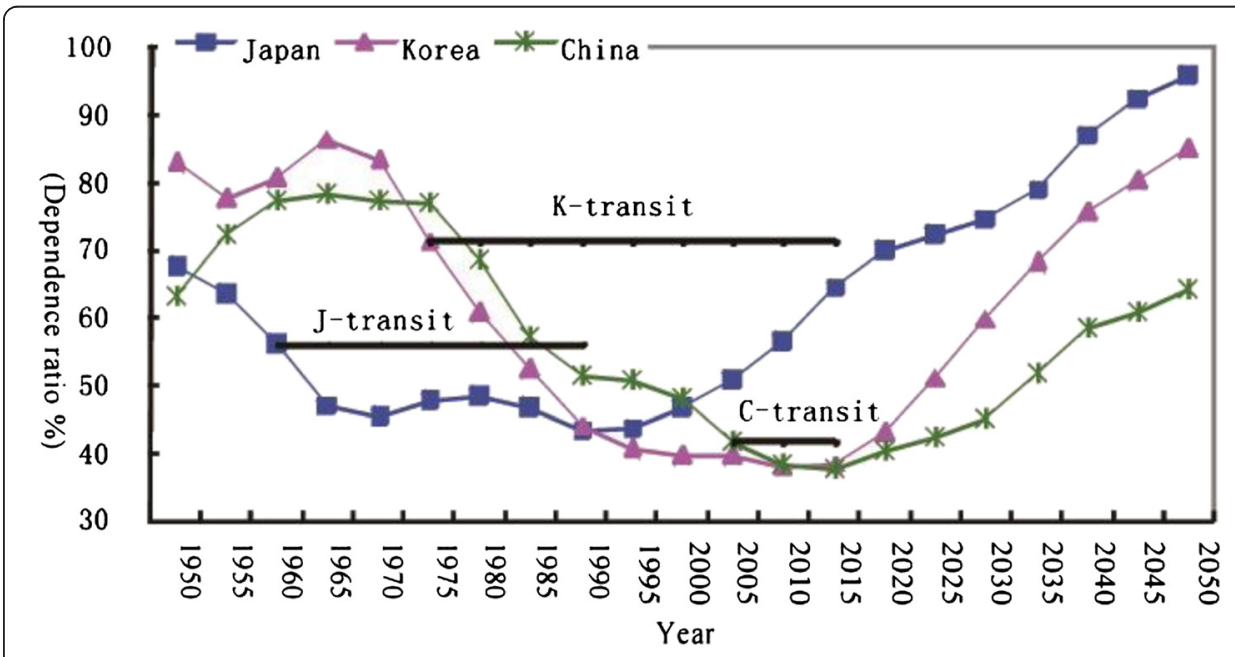

Fig. 2 Time spans between two turning points: Japan, South Korea, and China. Source: United Nations (2011) 
(2009), China's average annual potential GDP growth rate was $9.9 \%$ between 1978 and 1994 and $9.6 \%$ between 1995 and 2009 and is estimated to be 8.4 \% between 2010 and 2015 and $7.0 \%$ between 2016 and 2020. The estimate by Lu (2012) is relatively pessimistic - that is, while China reached its average annual potential GDP growth rate of $10.39 \%$ between 1978 and 1994 and $9.76 \%$ between 1995 and 2009, it is estimated to drop to $7.79 \%$ during the period of the 12th Five-Year Plan and drop further to $6.31 \%$ during the period of the 13th Five-Year Plan (see Fig. 3).

Because demographic transition in China has been much faster than observers could have predicted, it stands to reason that the aforementioned forecasts may still be an overestimation of China's potential GDP growth rate. According to a widely known estimate, the 15-64-year-old working-age population in China is expected to stop growing in 2013 and begins to decline afterward. The reversal of the dependency ratio is also predicted to occur in the same year. According to the sixth national census conducted in 2010, however, the population aged 15-59 years old already stopped growing in 2010 because of low longterm fertility levels (China Development Research Foundation 2012, Chapter 10). ${ }^{2}$ As a result, labor supply constraints may be much more serious than is commonly thought.

Similarly, since it is difficult to assess the severity of diminishing returns on capital accurately, most predictions will be based on an overestimation of capital supply potentials. More importantly, with the substantial reduction in surplus labor in agriculture, it will now be impossible to achieve resource reallocation efficiency as easily as in the past. Also, the technology gap between China and developed nations has been narrowing gradually, which has pared down on what relative advantage China used to be able to claim on the basis of its backwardness. This is making continued technological progress and future growth both increasingly difficult. All this can lead to a significant slowdown to the growth of TFP.

\section{Results and discussion}

\section{High costs of pursuing high growth rates}

If the Chinese government, at either the central or the local level, will not accept the slowdown of the potential growth rate, it would need to establish leverages in order to

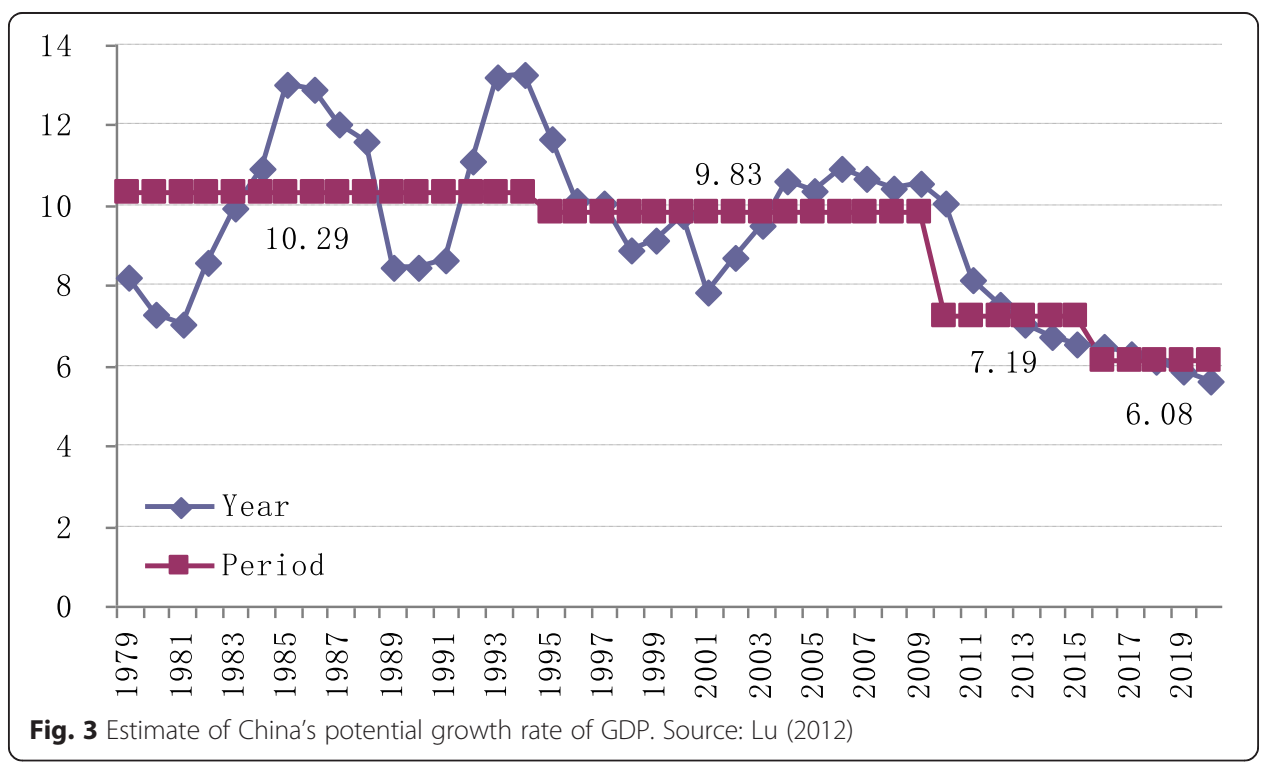


exert outside forces beyond the market force to achieve a real growth rate that is higher than the potential growth rate. They may achieve this by instituting industrial policies aimed at seeking dynamic comparative advantages, regional development strategies focused on fostering new economic growth points, and stimulus packages targeted at maintaining a higher growth rate. As international experience has demonstrated, however, high growth rates achieved in this way can undermine sustainable growth.

First, the pursuit of excessively high growth rates by means of frequent macroeconomic regulations will invariably lead to macroeconomic instability and damage the climate in which small- and medium-sized enterprises (SMEs) operate and grow. Stimulus policies are intended to pursue a real growth rate higher than the potential growth rate, which can introduce volatility into the macroeconomy and also aggravate existing imbalances within the economy. Apart from the potential risks of the bubble economy, the introduction of tightening policies due to concerns about inflation following stimulus policies often harms SMEs, because large state-owned enterprises (SOEs) and state investment projects are usually protected, while SMEs become the sole targets of regulation. The regulatory process itself will inevitably lead both SMEs and the private economy to become the first casualty even in the absence of overt policy discrimination against them.

For example, during periods of tightened monetary supply when reserve ratio and benchmark interest rate are raised, bank loans are usually directly controlled through "window guidance" designed to protect only those healthy and sustainable investments. However, in the implementation of "window guidance," local branches of commercial banks tend to protect large SOEs and state investment projects and to apply pressure to SMEs and private projects. This is because the former has government guarantees and risk-free soft budget constraints and as such need not be concerned with their ability to repay the loans, but the latter can only rely on competition to survive. In this case, SMEs will tend to face more stringent financial constraints than large enterprises.

At the new development stage, the increase of productivity relies overwhelmingly on the ability of SMEs to innovate. Macroeconomic instability and the negative impacts on SMEs associated with it can hinder the improvement of TFP, thereby hampering the economic growth rate.

Second, pursuing excessively high growth rates will lead to prices distortions for production factors and compromise comparative advantages. Strenuous promotion of largescale investment means too much investment of cheap capital, which drives down the relative price of capital, resulting in increased capital intensity, which not only detracts from China's comparative advantages but also aggravates diminishing returns on capital.

For example, the capital-labor ratio of the manufacturing industry in China's central and western regions has undergone a rapid upward trend after 2000, with a growth rate higher than that in coastal regions. After climbing rapidly in 2003 and 2004, the absolute level of capital intensity in the central and western regions has been higher than that in the coastal regions. In 2007, the capital-labor ratio of manufacturing was $20.1 \%$ in the central provinces and $25.9 \%$ in the western provinces, both higher than in the eastern regions. In other words, while the central and western regions do not enjoy comparative advantages in capital-intensive industries, manufacturing in those regions has become more capital intensive, and the heavy and chemical industries in those regions have grown considerably. 
Facts about China's economic growth indicate that as the working-age population growth rate falls, that is, as the demographic dividend diminishes, the Chinese economy can no longer be said to enjoy unlimited labor supply. Instead, the Chinese economy is increasingly in characteristic of neoclassical growth, and the increase of capital investment has already run up against diminishing returns on capital. This can be observed in the precipitous fall of the rates of marginal return for capital, as well as the accelerated growth of capital investment (see Fig. 4).

Third, the pursuit of excessively high growth rates will lead to resource wastage and will aggravate excess capacity. Investment behaviors originating from factors extrinsic to the market can easily lead to resource malallocation and lower investment efficiency, which will result in excess capacity. For countries playing catch-up, and especially when they are speeding up with respect to gains in comparative advantages, it is not unusual for their governments to intervene directly in investment activities in order to discover which sectors and regions possess potential competitive advantages and to seize growth opportunities. As seen in China, such government intervention may be manifested in a series of government strategies and policies. On the whole, emerging strategic industries with comparative advantages that the government has chosen to give strong support usually involve large-scale investment, long construction cycles and are technologically exploratory and experimental. Once their preferential status is established, investment and construction may experience a surge.

Historical experience indicates that the main objective of developing nations when they are working toward catching up with developed nations is achieving a certain industrial structure. That is to say, when forecasting their own dynamic comparative advantages, enterprises tend to take the development of certain capital- and technologyintensive industries as a means for catching-up. When both enterprises and investors predict high comparative advantage, an investment surge follows (Lin 2007). When the government intervenes in investment activities, the scale of government investment and its guiding investment philosophy may be loaded with a variety of preferences, and even large subsidies. This may lead to an enlargement effect, which leads the investment to flock toward the same direction or the same region.

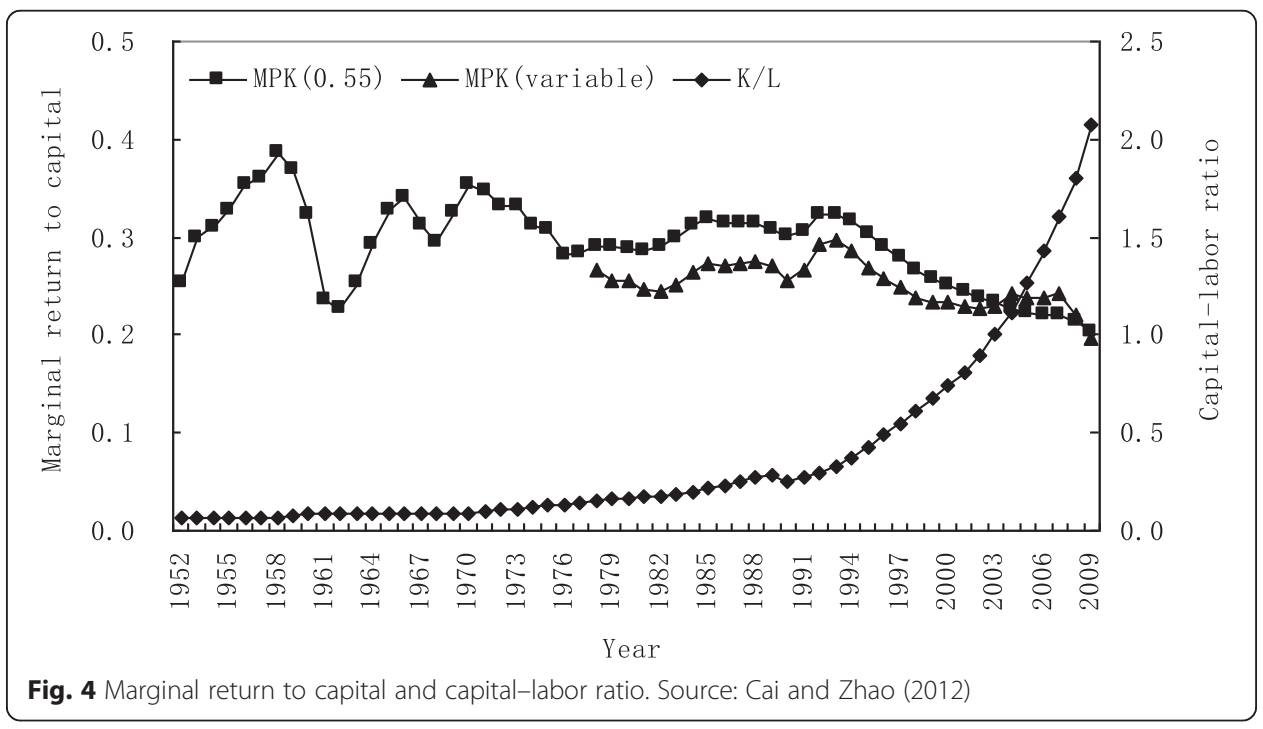


It is inherently contradictory that the Chinese government has made great efforts to resolve the problem of excess capacity and repetitive construction projects on one hand while creating excess capacity by implementing industrial policies ostensibly aimed at improving infrastructure regional development strategies, industrial revitalization, and development of strategic emerging industries on the other.

Not surprisingly, due to the recent wave of investment, those industries targeted by industrial policies and regional development strategies as leading industries often suffer the most severe excess capacity. In 2010, with the exception of some industries that are internationally competitive, such as the textile industry and light industry, the utilization rate of production capacity of most targeted industries was significantly lower than the average rate of industrial production capacity utilization (82\%). Of those, the production capacity utilization rate was less than $50 \%$ in the steel industry and $70 \%$ in the nonferrous metal industry (Qu 2012).

Finally, pursuing an excessively high growth rate will lead to overprotection of inefficient enterprises and hinder the improvement of TFP. In the name of securing employment and maintaining GDP growth and tax revenue, those enterprises which should have been eliminated due to poor performance are subsidized and protected from collapse. This practice will result in saving underperforming production capacity, damaging competition mechanisms, and creating zombie enterprises.

China still has an advantage in the backwardness of its economic development. In many fields, such as systemic reform, increase of management efficiency, and application of new technologies, there are still some low-hanging fruits to harvest so as to improve significantly microeconomic production efficiency. To obtain such efficiency, and to maintain sustainable growth, China should promote innovation within enterprises, which should choose their own management methods and technological routes so as to maximize efficiency. However, that would require the government to exercise restraints in micro-management of the economy.

There is an ancient Chinese saying that, "there is no construction without destruction, no flowing without damming and no motion without rest". This is essentially a reference to the phenomenon of creative destruction such as discussed by Joseph Schumpeter. What it means is that new economic structures are built from the rubble of older ones. Without an environment of creative destruction, inefficient enterprises will not die and efficient ones would not come into being. Without the dominant role of TFP, economic growth cannot be sustained in the environment closer to the neoclassical scenario.

\section{Tapping new sources of economic growth}

The aforementioned points demonstrate that economic transition in China from one development stage to the next is going to slow down growth. Therefore, it would be improper to implement policies intended to achieve by arbitrary means growth rates that are higher than the potential growth rate, because that would in many cases hurt long-term sustainability of the economy. It is necessary, therefore, for policymakers to be willing to accept constraints to the growth rate. However, the potential growth rate can change, that is, it can be increased via tapping relevant factors of production, especially the potential labor supply, and improving TFP, so as to achieve a higher economic growth rate. There is still a large window of opportunity for increasing the potential growth rate of the Chinese economy through reform. 
The main reason we now predict a slowdown of China's potential growth rate is the trend in labor supply. As the working-age population stops growing, not only will the labor supply itself restrict economic growth but more importantly, labor shortages will generate diminishing returns on capital, which has exerted little constraint on Chinese economic growth through the period of unlimited labor supply. Therefore, if the potential labor supply can be further developed and human capital significantly improved, not only factor bottlenecks but also diminishing returns on capital will be mitigated.

In addition, as China's economy increasingly tends toward neo-classical growth, longterm sustainable growth will ultimately depend on the transition from input-driven factors to TFP-driven patterns. Therefore, to increase the potential growth rate, it is important for us to explore how to improve TFP.

First, there is still a huge potential for rural labor transfer. In general, increasing the labor participation rate can increase the potential growth rate once labor has become a constrained factor of economic growth (Cai and $\mathrm{Lu} \mathrm{2012).} \mathrm{For} \mathrm{the} \mathrm{next} \mathrm{5-10} \mathrm{years,} \mathrm{to}$ further promote migration of rural laborers toward urban non-agricultural sectors in order to stabilize the supply of labor is a distinctly Chinese way of improving the labor participation rate. In 2010, China's urbanization rate reached $49.95 \%$. However, the population share of non-agricultural household registration, or hukou, accounted for only $34.17 \%$. The difference between the two was mainly due to the fact that rural laborers working in cities for over 6 months cannot obtain urban hukou.

The fact that the migrant workers seeking jobs in eastern cities are still registered as permanent residents of the central and western rural areas means that they cannot live in working areas permanently until they have reached a certain age, as per regulations of the existing hukou system. Therefore, they usually have to return home to live the life of a farmer upon reaching their late 30s or early 40s, which substantially decreases the labor force participation rate.

The situation whereby migrant workers are counted as urban residents but cannot obtain an urban hukou has led not only to unequal provision of urban public services but also to instability in labor supply, as they comprise more than a third of the workforce in urban areas. Therefore, as labor-intensive industries are increasingly relocated from coastal regions to central and western regions, the provision of full access to public services to migrant workers should be made a hukou system reform priority. This reform can eliminate institutional barriers to rural labor mobility, expand the geographic and industrial scope of the further transfer of rural labor, and increase the total labor supply.

Second, the accumulation of human capital should be intensified. It is estimated based on labor data that 1.3 years of schooling is required for a worker in a laborintensive secondary industry to transition into a capital-intensive secondary industry and 4.2 years to transition into a technology-intensive tertiary industry. This is a longtime investment for workers to bear. Even though the government extended the number of years of compulsory education and increased enrollment in colleges and universities, the average length of education of the population over 16 years old increased only from 6.24 to 7.56 years between 1990 and 2000, an increase of only 1.32 years. That figure was up to 7.88 years in 2005 , an increase of only 0.32 year over 5 years.

To facilitate a better education for future workers, it is necessary to maintain rapid development of various types of education at all levels, including higher education. For 
a long time, it has been mainly the extension of compulsory education that has increased the average duration of education of Chinese workers. As the rude enrollment rate of compulsory education is now up to $100 \%$, it will be necessary to popularize senior high school and higher education in order to continue to increase the figure.

Increased attendance of senior high school leads to higher enrollment in universities, just as increased enrollment in universities promotes increased high school attendance. The higher the attendance rate of the high schools, the greater the proportion of the population that desires to enroll in colleges and universities. Conversely, when there are more opportunities to enroll in colleges and universities, a larger percentage of the population is motivated to enroll in high schools. At present, the government budget for senior high school expenditures is comparatively low, which results in an overburden on household expenditures, plus a high opportunity cost and a low passing rate on the college entrance examination. So high school may in the future become a bottleneck for the development of education. Therefore, assuming the continued and rapid popularization of higher education, the government should promote free high school education. On the other hand, the government should encourage social investment and family investment in higher education.

Finally, it is urgent to open up new areas of the economy to increase the TFP. At this stage of a typical dual economy, simply transferring labor can bring about a huge productivity spike, as there is surplus labor in agriculture and agricultural productivity is significantly lower than in non-agricultural industries. This resource reallocation efficiency gain has been an important driver of TFP growth over the past 30 years of China's economic development. As China has now reached the Lewis point and agricultural labor surpluses are dwindling, large-scale labor transfers will inevitably slow down. This will also change the process whereby TFP is improved.

Specifically, as shown in Fig. 5, as China's economy transitions toward neo-classical growth from the dual economy, the sources of TFP will shift from reallocation of resources among the primary, secondary, and tertiary to reallocation within the secondary

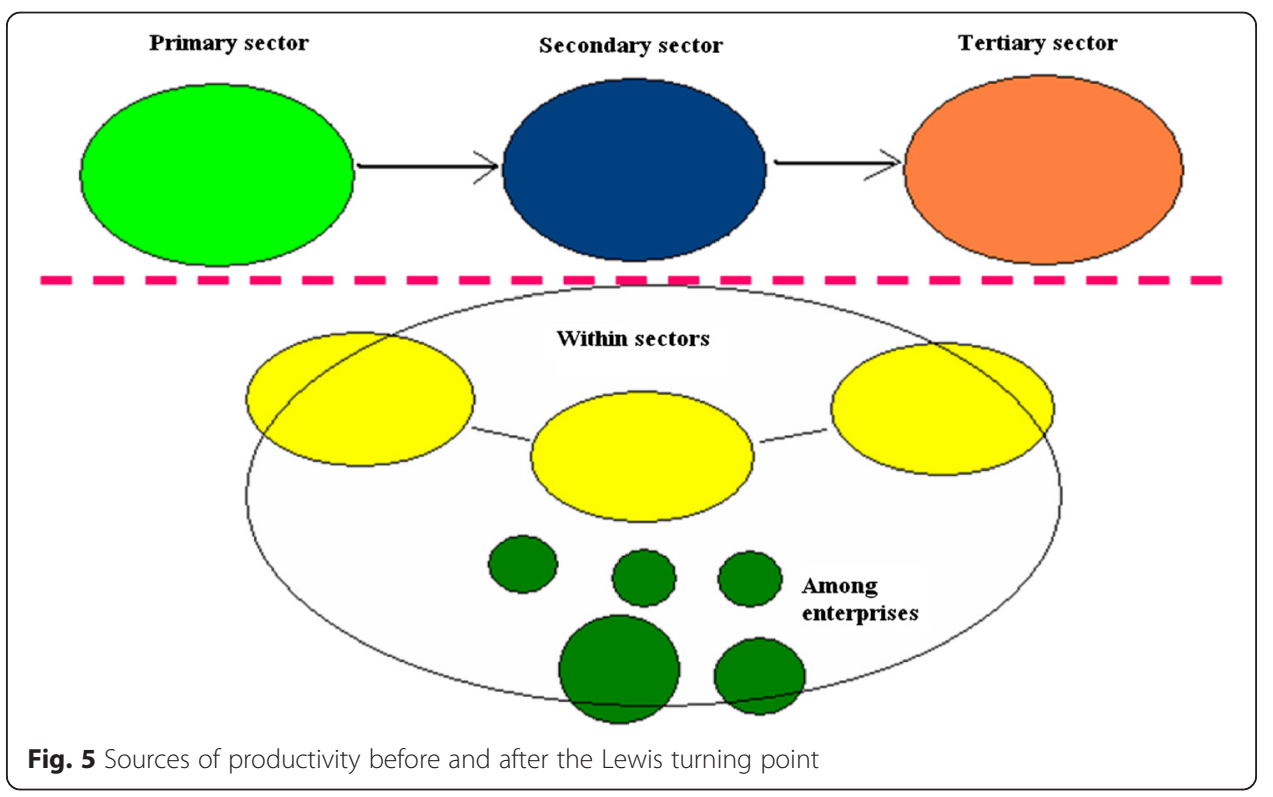


and tertiary industries, until all resources within a given sector have been reallocated among various enterprises.

The next 10 years will be a critical period for China as it tries to go from an uppermiddle income country to a high-income country. As compared to middle-income countries with a per capita GDP of 6,000-12,000 USD, China still has huge potential for transitioning its agricultural labor into industrial labor. By compiling the data for several nations in similar developmental stages in 1997, we discovered that the average proportion of agricultural labor in those nations was $14.8 \%$, nearly 20 percentage points lower than officially reported figures and 10 percentage points lower than scholarly figures estimated in China. ${ }^{3}$ This means that in the next 10 years, China needs to reduce its current agricultural labor population of 192 million by at least 2 million or $1 \%$ annually. This would allow China to continue to improve in resource reallocation efficiency and to make progress toward the sustainable economic growth.

However, as a period of neoclassical growth is coming-namely, less and less surplus labor force in agriculture-resource reallocation efficiency among the primary, secondary, and tertiary industries will eventually recede. The following sources may improve TFP more in the future. First, there are differentials in productivity between the secondary and tertiary industries; thus promoting the movement of production factors toward subsectors with higher productivity can help to achieve higher resource reallocation efficiency. Second, there are disparities in productivity among enterprises within a sector, thus allowing the more efficient enterprises to mature, to expand their scale and to dominate in the sector, while at the same time eliminating inefficiently run enterprises. This will help raise the efficiency of the sector and of the economy on the whole.

To achieve higher TFP by such means, it is necessary to lift the exit and entry barriers in the industrial sectors and the institutional barriers to production factor mobility. It is also necessary to introduce competition mechanisms to enable enterprises that perform well to prosper and those that perform poorly to be eliminated.

\section{Conclusions}

As an economy's potential growth rate slows, it is facile for officials to try to spur the real GDP growth rate to a higher level than the potential growth rate by means of overarching industrial policies, regional development strategies, and stimulus policies, because they produce immediate effects and can be implemented by use of tangible tools. It is thus tempting for the policymakers to adopt such policies frequently. Moreover, enhancing the potential growth rate will rely mostly on deepening reforms across the board in many fields. Since there is no longer any "low-hanging fruit" for reform, it will be more difficult to make use of the old strategies.

As Kharas (2011) (known for coining the concept "Middle Income Trap") points out, it would take 10 years or more for the intended effects of reform to materialize, including the development of a capital market, acceleration of innovation and development of higher education, improvement of urban management, livable city construction, formation of the agglomeration effect, effective rule of law, separation of powers, and reduced corruption. Therefore, the protracted nature of the reforms to potential growth rates often leads the decision-makers to return to their tried and trusted economic tricks. 
Although deepening reforms is undoubtedly the only way for China to sustain longterm economic growth, one should not take a utilitarian view on reform. In other words, one should not expect reforms to produce immediate effects on economic growth. On one hand, it is necessary to push reforms to a new height to build institutional conditions for long-term sustained growth. On the other, it is imperative to prepare to adapt to and to accept reduced growth rates similar to those experienced during neo-classical growth, which would be necessary for transition from the "low-hanging fruit" economic growth pattern of quantity into a productivity-centric model focused on quality.

\section{Endnotes}

${ }^{1}$ For details of data and methods of the estimation, see Cai and Lu (2012) and Kuijs (2009).

${ }^{2}$ Most scholars and United Nations' official reports believe China's total fertility rate is about 1.4-1.5, while some argues that it has fallen to 1.18, based on census in 2010 (Mu 2012).

${ }^{3}$ It may be found that the total number of actual farm labor in China is 192 million, accounting for $24.7 \%$ of the total labor force, by classifying the labor inputs in different economic activities of the rural labor force monthly and individually instead of classifying the labor employment annually. (Du and Wang 2011).

\section{Competing interests}

The author declares that he has no competing interests.

Received: 17 September 2012 Accepted: 11 October 2012

Published online: 18 June 2015

\section{References}

Amornthum S (2002) Japan's potential growth: an HP filter approach, research paper for Econ 614 economic development of Japan. Department of Economics, University of Hawaii at Manoa.

Bai M (1982) The turning point in the Korean economy. Dev Econ 20(2):117-140

Cai F, Zhao W (2012) When demographic dividend disappears: growth sustainability of China. In: Masahiko A, Jinglian W (eds) The Chinese economy: a new transition. Palgrave Macmillan, Basingstoke

China Development Research Foundation (2012) China development report (2011/12): development in population, economy and society in harmony. China Development Press, Beijing

Du Y, Wang M (2011) Number and structure of China's employment: re-estimates and discussions. In: Cai F (ed) The reports on China's population and labor (No.12): challenges during the 12th five-year plan period: population, employment and income distribution. Social Sciences Academic Press, Beijing

Ikeda N (2012) Lost Two decades: truth about the long-term stagnation of the Japanese economy (the Chinese translation). China Machine Press, Beijing

Kharas H (2011) China's transitions to a high income economy: escaping the middle income trap. In: Lim E, Spence M (eds) The medium and long term development and transformation of the Chinese economy: an international perspective. CITIC Publishing House, Beijing, pp 470-501

Kuijs L (2009) China through 2020-a macroeconomic scenario, World Bank China research working paper No. 9.

Lin JY (2007) Wave phenomenon and the reconstruction of macroeconomic theories for developing countries. Econ Res J 1:126-131

Lu Y (2012) China's potential output growth rate and estimates. In: Cai F (ed) The reports on China's population and labor (no. 13): demographic transition and rebalancing China's economic growth. Social Sciences Academic Press, Beijing

Minami R (1968) The turning point in the Japanese economy. Q J Econ 82(No.3):380-402

Mu G (2012) Negative population growth concept hindering China's revitalization, global times, July 21

Qu Y (2012) Growth rate driven by large-scale of investment: research on overcapacity of production. In: Cai F (ed) The reports on China's population and labor (no.13): demographic transition and rebalancing China's economic growth. Social Sciences Academic Press, Beijing

United Nations (2011) Department of Economic and Social Affairs, Population Division, World Population Prospects: The 2010 Revision, CD-ROM Edition 